\title{
Effect of aliskiren on cardiovascular outcomes in patients with prehypertension: a meta-analysis of randomized controlled trials
}

This article was published in the following Dove Press journal:

Drug Design, Development and Therapy

2 April 2015

Number of times this article has been viewed

\author{
Jing-Tao Zhang \\ Ke-Ping Chen \\ Ting Guan \\ Shu Zhang
}

Cardiac Arrhythmia Center, Fuwai Hospital, National Center for

Cardiovascular Diseases, Chinese Academy of Medical Sciences and

Peking Union Medical College, Beijing,

People's Republic of China
Correspondence: Ke-Ping Chen Cardiac Arrhythmia Center, Fuwai Hospital, National Center for Cardiovascular Diseases, Chinese Academy of Medical Sciences and Peking Union Medical College, 167 Beilishi Road, Beijing 100037, People's Republic of China

Tel +86 I0 88398866

Email chenkepingbj@yeah.net
Background: Aliskiren is a widely used therapy for patients with hypertension, however, the effect of aliskiren on major cardiovascular outcomes is a matter of debate. The aim of this study is to evaluate the effects of aliskiren therapy on major cardiovascular outcomes by this meta-analysis of randomized controlled trials.

Methods: We searched PubMed, EmBase, and the Cochrane Central Register of Controlled Trials for relevant literature. All eligible studies were randomized controlled trials assessing the effect of aliskiren therapy compared with patients without aliskiren therapy. Relative risks (RRs) with 95\% confidence intervals (CIs) were used to measure the effect of aliskiren therapy on major cardiovascular outcomes with a random-effect model.

Results: We included six trials reporting data on 12,465 patients. These studies reported 1,886 occurrences of major cardiovascular events, 1,074 events of total mortality, 739 events of cardiac death, 366 events of myocardial infarction, and 319 events of stroke. Aliskiren therapy had no effect on major cardiovascular events (RR, $0.93 ; 95 \% \mathrm{CI}: 0.77-1.13 ; P=0.47)$, total mortality (RR, 1.00; 95\% CI: 0.77-1.29; $P=1.00$ ), cardiac death (RR, 1.01; 95\% CI: 0.79-1.29; $P=0.95$ ), myocardial infarction (RR, $0.71 ; 95 \% \mathrm{CI}$ : $0.36-1.38 ; P=0.31)$, or stroke (RR, $0.87 ; 95 \% \mathrm{CI}$ : $0.48-1.58 ; P=0.64)$.

Conclusion: Aliskiren therapy does not have an effect on the incidence of major cardiovascular events, total mortality, cardiac death, myocardial infarction, or stroke.

Keywords: aliskiren, cardiovascular disease, stroke, systematic review, meta-analysis

\section{Introduction}

Hypertension is the leading cause of premature morbidity for both men and women. It raises considerable public concern, because it increases the prevalence of severe cardiovascular disease, stroke, diabetes, and other systemic diseases, causing great costs and burden to both society and families. ${ }^{1}$ Around 73 million adults in the US have hypertension, and approximately $30 \%$ of these patients have stage 2 hypertension. ${ }^{2}$ These patients are at increased cardiovascular risk compared to the risk for those with smaller elevations in blood pressure (BP). Therefore, achieving BP control in these patients is necessary to reduce cardiovascular risk. However, in approximately $30 \%$ of patients, BP returns to pretreatment levels or higher during ongoing treatment. ${ }^{3,4}$ Thus, it is necessary to develop additional effective treatment schemes.

Inhibition of the renin-angiotensin system (RAS) with angiotensin-converting enzyme inhibitors (ACEIs) or angiotensin receptor blockers (ARBs) has proved to be a successful strategy for the treatment of hypertension. ${ }^{5-7}$ Aliskiren is the latest addition to drugs that block the RAS. Its primary indication is as an antihypertensive 
agent, in combination with ACEIs or ARBs for BP control. ${ }^{8}$ The clinical efficacy of these drugs when used individually for BP control has been shown in several randomized controlled trials. ${ }^{5-11}$ However, the effect of aliskiren therapy on cardiovascular outcomes has not been confirmed by any trials. A previous meta-analysis ${ }^{12}$ showed the efficacy and safety of dual blockade of the RAS. Although this treatment showed a slight beneficial effect on certain surrogate endpoints, it failed to reduce mortality and was associated with an excessive risk of adverse events, such as hyperkalemia, hypotension, and renal failure. Furthermore, although the study incorporated aliskiren, it also included other therapies for dual blockade of the RAS. This leads to uncertainty regarding the cardiovascular protective effects of aliskiren therapy. Therefore, we conducted a meta-analysis of pooled data from randomized controlled trials, including the latest evidence of the effects of aliskiren therapy on the risk of cardiovascular outcomes.

\section{Methods}

\section{Data sources, search strategy, and election criteria}

Randomized controlled trials of aliskiren therapy in English language literature were eligible for inclusion in our research, regardless of publication status (published, in press, or in progress). We performed our search in PubMed (inception to September 2013), EmBase (inception to March 2013), and the Cochrane Library (inception to September 2013) by using selected common keywords pertaining to aliskiren in randomized controlled trials. We searched the bibliographies of relevant articles in order to identify additional studies of interest. For studies that did not directly report the efficacy and safety of aliskiren, we also contacted the authors in the field for any unpublished data. However, they did not have any available data to use in our meta-analysis. Studies were eligible for inclusion when they met the following requirements: 1) the study was a randomized controlled trial; 2) the study investigated the effects of aliskiren therapy; and 3 ) the study reported at least one of the following outcomes: major cardiovascular events, total mortality, cardiac death, myocardial infarction, and stroke.

The literature search was undertaken independently by two authors with a standardized approach, and any disagreement between these two authors was settled by a third author until a consensus was reached. This review was conducted and reported according to the Preferred Reporting Items for Systematic Reviews and Meta-Analysis (PRISMA) Statement issued in 2009. ${ }^{13}$

\section{Data collection and quality assessment}

All studies retrieved from databases and bibliographies were independently evaluated by two authors of this paper. Of the articles found in the three databases, duplicate articles and those that did not meet the selection criteria were excluded. We extracted the following data from the remaining studies: first author or study group name, year of publication, number of patients, mean age, percentage male, disease status, intervention, study duration, and reported outcomes. Data abstraction was also performed in duplicate, as was study selection. We measured the quality of the trials included in this study with the Jadad score ${ }^{14}$ based on randomization, concealment of treatment allocation, blinding, completeness of follow-up, and the use of intention-to-treat analysis.

\section{Statistical analysis}

We allocated the results of each randomized controlled trial as dichotomous frequency data. Individual study relative risks (RRs) and 95\% confidence intervals (CIs) were calculated from event numbers extracted from each trial before data pooling. Both fixed-effects and random-effects models were used to evaluate the pooled RR for aliskiren therapy. Although both models yielded similar findings, results from the random-effects model presented here assume that the true underlying effect varies among included trials..$^{15,16}$ Heterogeneity of the treatment effects between studies was investigated visually using a scatter plot analysis as well as statistically using the heterogeneity $I^{2}$ statistic. ${ }^{17,18}$ Subsequently, subgroup analyses were conducted for major cardiovascular events and total mortality on the basis of current disease status, control, and the duration of follow-up. We also performed a sensitivity analysis by removing each individual trial from the meta-analysis. Visual inspection of funnel plots for major cardiovascular events and total mortality was conducted, and Egger ${ }^{19}$ and Begg $^{20}$ tests were used to assess publication bias statistically and quantitatively. All reported $P$-values are two-sided, and $P$-values of less than 0.05 were regarded as statistically significant for all included studies. Statistical analyses were performed using STATA software (version 10.0) (StataCorp LP, College Station, TX, USA).

\section{Results}

A total of 311 articles were identified by searching the three databases and relevant bibliographies. We excluded 272 articles that did not satisfy the selection criteria. After the full text for the remaining 39 articles was reviewed, 33 articles were excluded. As a result, we included six randomized controlled trials, ${ }^{9,11,21-24}$ which ultimately met our 
inclusion criteria (Figure 1). Table 1 summarizes the characteristics of these trials and the important baseline information of the included 12,758 individuals. The follow-up periods for participants ranged from 8 weeks to 32.9 months, and the number of individuals included in each trial ranged from 550 to 8,561 . The primary outcomes were major cardiovascular events available in five trials, ${ }^{9,11,22-24}$ total mortality in six trials, ${ }^{9,11,21-24}$ cardiac death in four trials, ${ }^{9,11,22,24}$ myocardial infarction in four trials, ${ }^{9,11,22,24}$ and stroke in three trials. ${ }^{9,11,24}$ Although the included trials rarely reported on the key indicators of trial quality, the quality of the trials was also assessed by the Jadad score. ${ }^{13}$ Overall, three trials ${ }^{11,21,24}$ had a Jadad score of 5, and the remaining three trials ${ }^{9,22,23}$ had a score of 4 .

Data for the effect of aliskiren therapy on major cardiovascular events included 12,155 individuals and reported 1,886 major cardiovascular events. Overall, aliskiren therapy reduced the risk of major cardiovascular events by $7 \%$, but this difference was not statistically significant (RR, 0.93; 95\% CI: $0.77-1.13 ; P=0.47$; Figure 2A). Although substantial heterogeneity was observed in the magnitude of the effect across the trials included $\left(I^{2}=67 \% ; P=0.02\right)$ a sensitivity analysis indicated that the results were not affected by sequential exclusion of any particular trial from all pooled analysis.

Data for the effect of aliskiren therapy on total mortality included 12,758 individuals and 1,074 death events. There were no differences observed between patients receiving aliskiren therapy versus those receiving ACEI or ARB therapy for total mortality (RR, 1.00; 95\% CI: 0.77-1.29;

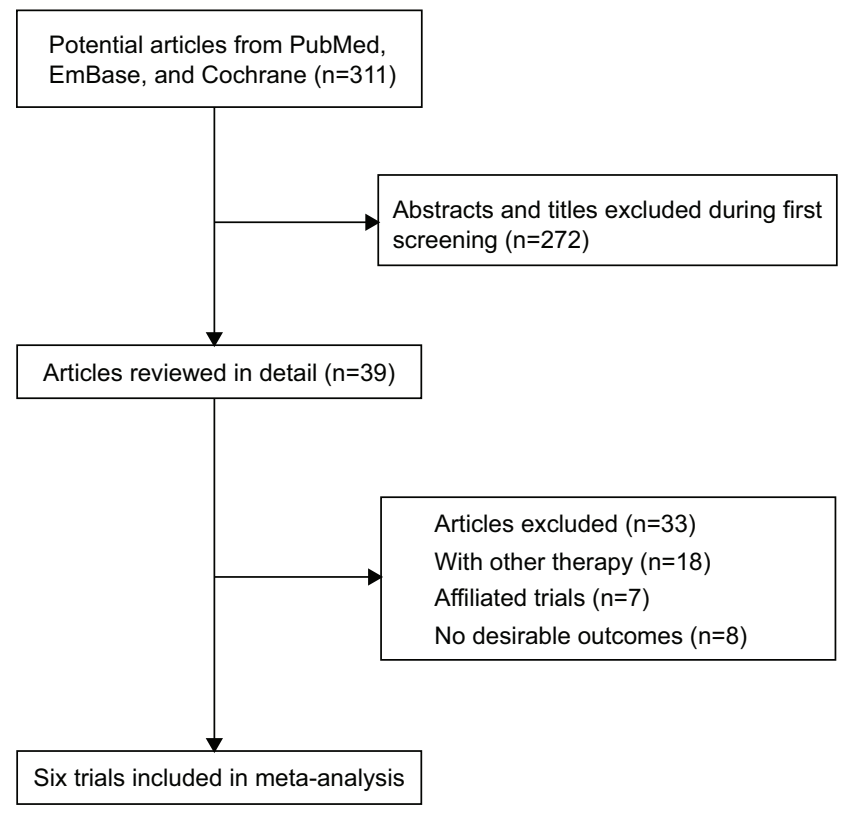

Figure I Flow diagram of the literature search and trial selection process.
$P=1.00$; Figure 2B). Although there was some evidence of heterogeneity across the studies included, the results were not affected by exclusion of any specific trial $\left(I^{2}=47 \%\right.$; $P=0.09$ ).

Data for the effect of aliskiren therapy on cardiac death included 11,335 individuals and 739 events of cardiac death. We noted that aliskiren therapy did not have an effect on cardiac death (RR, 1.01; 95\% CI: 0.79-1.29; $P=0.95$; Figure 3A). Moderate heterogeneity was observed across included trials, after sequential exclusion of each trial from all pooled analysis, the results were not affected by exclusion of any specific trial $\left(I^{2}=43 \% ; P=0.15\right)$.

Data for the effect of aliskiren therapy on myocardial infarction included 11,335 individuals and 366 events of myocardial infarction. We noted that aliskiren therapy showed a $29 \%$ reduction in myocardial infarction; however, there was no supporting evidence to show it protected against myocardial infarction risk (RR, 0.71; 95\% CI: 0.36-1.38; $P=0.31$; Figure 3B). Heterogeneity was observed in the magnitude of the effect across the trials $\left(I^{2}=72 \% ; P=0.01\right)$. However, after sequential exclusion of each trial from all pooled analyses, the conclusion was not affected by the exclusion of any specific trial.

Data for the effect of aliskiren therapy on stroke included 10,789 individuals and 319 events of stroke. We noted that aliskiren therapy reduced the risk of stroke by $13 \%$, but this decrease was not statistically significant (RR, 0.87; 95\% CI: $0.48-1.58 ; P=0.64$; Figure $3 \mathrm{C}$ ). Heterogeneity was observed in the magnitude of the effect across the included trials $\left(I^{2}=61 \% ; P=0.08\right)$; however, after sequential exclusion of each trial from all pooled analyses, the results were not affected by exclusion of any specific trial.

Subgroup analyses were also performed for major cardiovascular events and total mortality to evaluate the effect of aliskiren therapy in a specific population. However, no significant differences were observed in predefined factors between those who received aliskiren therapy or other therapy (Table 2).

A review of funnel plots could not rule out the potential for publication bias for major cardiovascular events (Figure 4A) and total mortality (Figure 4B). In addition, Egger ${ }^{19}$ and Begg ${ }^{20}$ tests showed no evidence of publication bias for major cardiovascular events ( $P$-value for Egger, 0.322; $P$-value for Begg, 0.462 ), total mortality ( $P$-value for Egger, $0.430 ; P$-value for Begg, 0.260), cardiac death ( $P$-value for Egger, 0.348; $P$-value for Begg, 0.308), myocardial infarction ( $P$-value for Egger, 0.381; $P$-value for Begg, 0.734), and stroke ( $P$-value for Egger, 0.240; $P$-value for Begg, 1.000). 


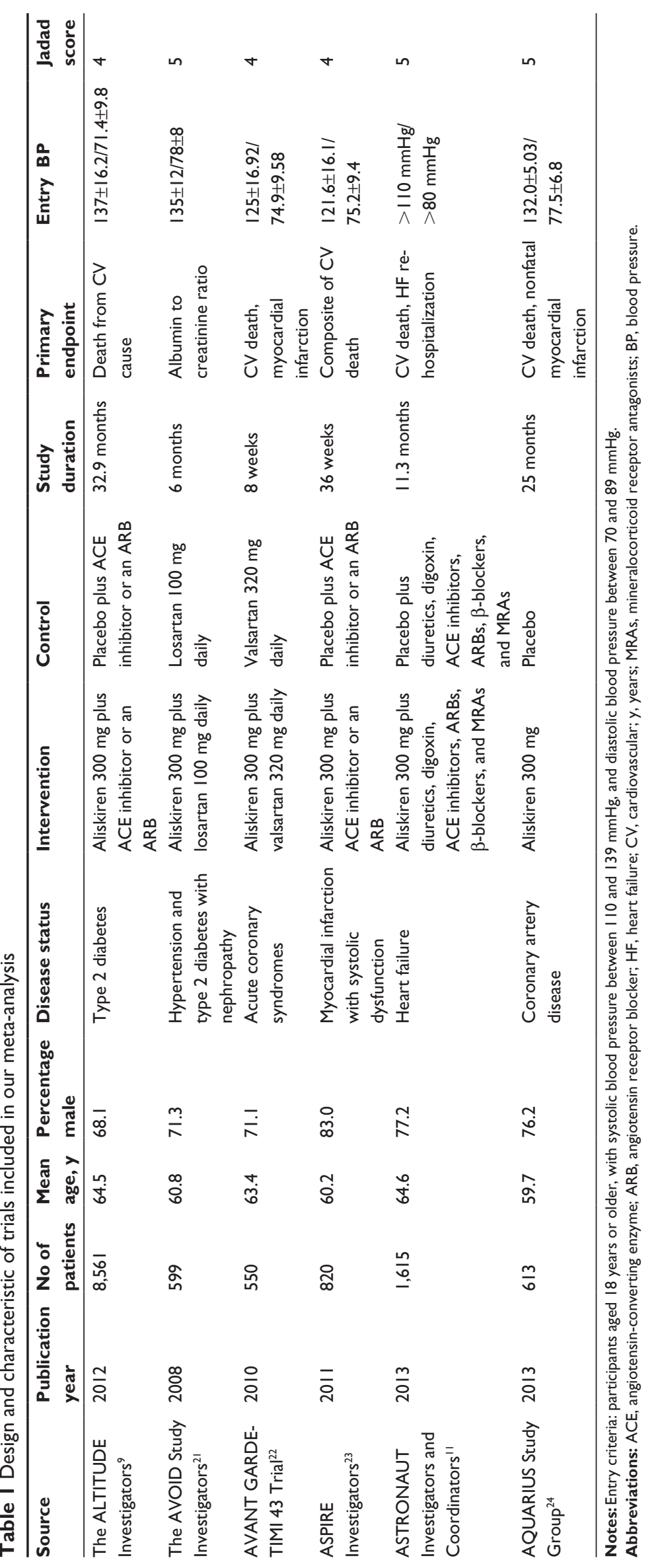




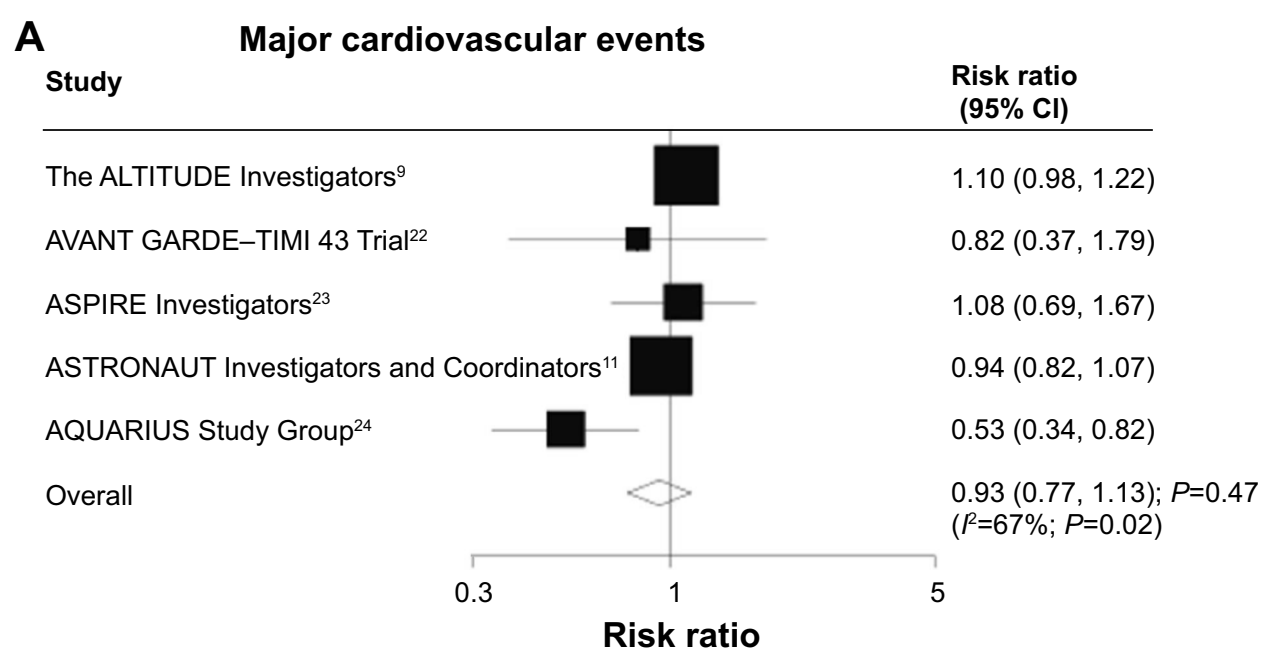

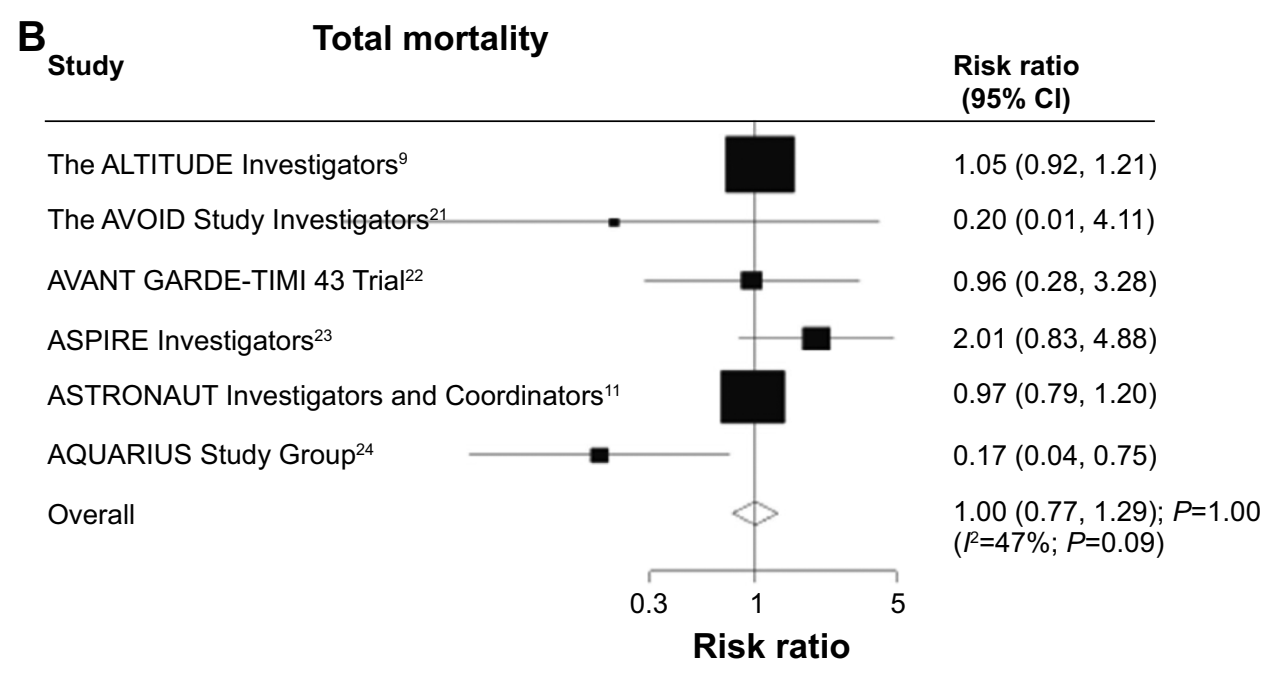

Figure 2 Effects of aliskiren therapy on the risk of major cardiovascular events $(\mathbf{A})$ and total mortality (B). Abbreviation: $\mathrm{Cl}$, confidence interval.

\section{Discussion}

Several previous trials ${ }^{5-7}$ have suggested that ACEI or ARB monotherapy provides an antihypertensive effect in hypertension patients, but certain patients with refractory hypertension are intolerant to ACEI or ARB therapy alone. It is necessary to find additional effective preventive therapies. Pool et $\mathrm{a}^{25}$ performed a randomized controlled trial of aliskiren, and indicated that aliskiren and valsartan in combination may provide additive BP-lowering effects with maintained tolerance. However, the ALTITUDE Investigators' trial ${ }^{9}$ concluded that the addition of aliskiren to standard therapy has no effect on cardiovascular outcomes; but the proportion of patients with hyperkalemia (11.2\% versus [vs] 7.2\%), or hypotension ( $12.1 \%$ vs $8.3 \%$ ) was significantly higher in the aliskiren group than in the placebo group, respectively. A previous review ${ }^{26}$ has evaluated the benefits and harms of aliskiren therapy versus ARB therapy in patients with hypertension on the basis of randomized controlled trials and suggested that combination therapy was superior to ARBs in controlling BP, and did not differ from ARB in risk of adverse events. Another important study ${ }^{27}$ encompassed a large body of literature spanning numerous cohorts, with different demographic characteristics, and concluded that combination therapy is associated with an increased risk for hyperkalemia. Our study was based on randomized controlled trials and explored the effect of aliskiren therapy on major cardiovascular outcomes.

Our comprehensive, quantitative study included 12,758 patients from six trials with a broad range of baseline characteristics. Although the studies included clinically diverse populations (different disease status), the results were consistent when subjected to various sensitivity analyses. The results of our meta-analysis suggest that aliskiren therapy has no effect on the incidence of major cardiovascular events, 

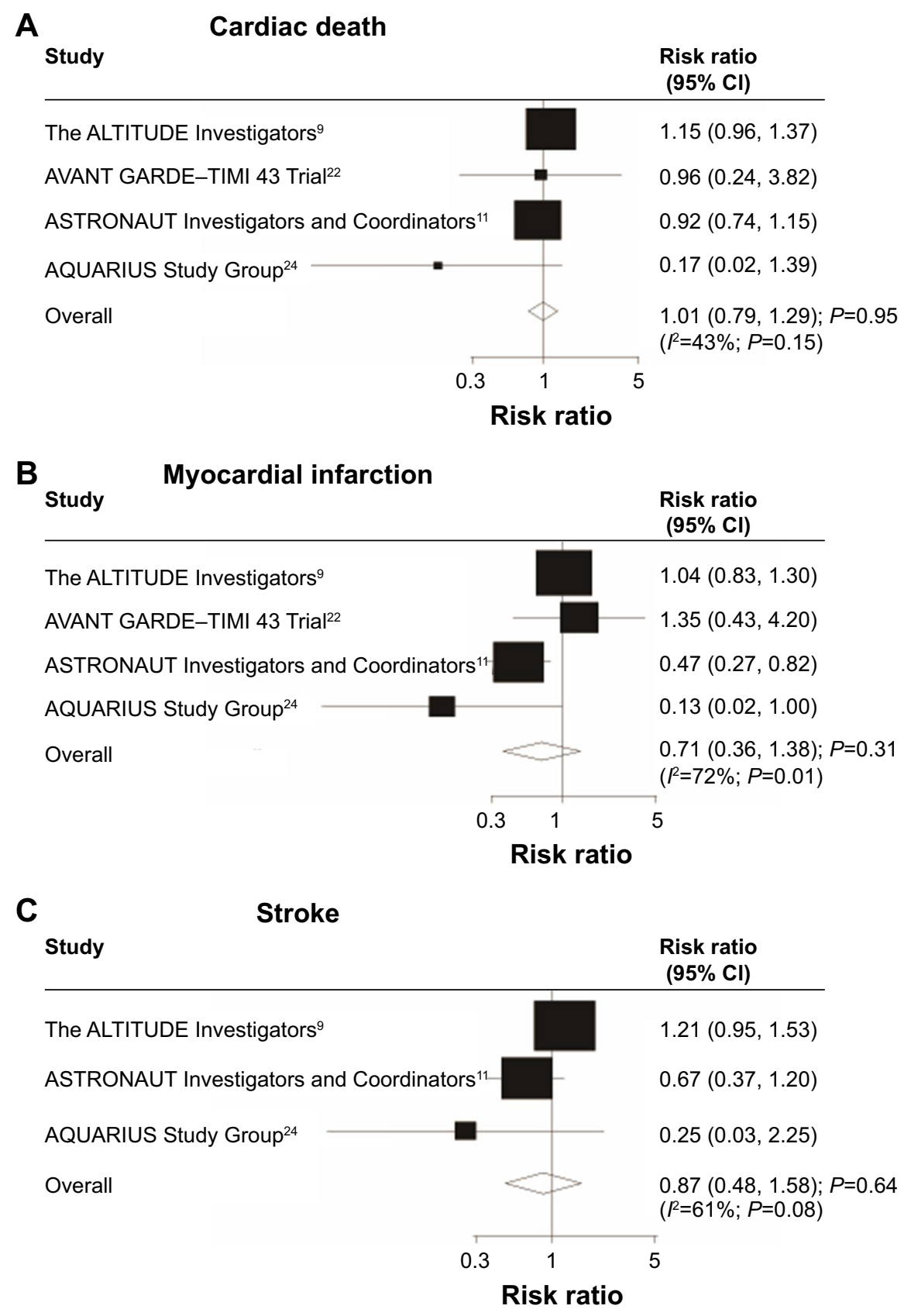

Figure 3 Effects of aliskiren therapy on the risk of cardiac death (A), myocardial infarction (B), and stroke (C). Abbreviation: $\mathrm{Cl}$, confidence interval.

total mortality, cardiac death, myocardial infarction, and stroke.

There were no significant differences between aliskiren therapy and ACEIs or ARBs alone for the RR of major cardiovascular events, total mortality, cardiac death, myocardial infarction, or stroke. Three large-scale randomized controlled trials of aliskiren therapy have been conducted recently. The ALTITUDE Investigators Study ${ }^{9}$ compared aliskiren therapy with ACEI or ARB therapy, and concluded that aliskiren therapy had no effect on cardiovascular and renal events, and it may even be harmful in patients with type II diabetes. Furthermore, ASTRONAUT Investigators and Coordinators' trial ${ }^{11}$ suggested that aliskiren plus standard therapy did not reduce major cardiovascular events (35.0\% vs $37.3 \%)$, death from any cause ( $17.8 \%$ vs $18.3 \%)$, cardiac death ( $15.6 \%$ vs $17.0 \%)$, and stroke ( $2.2 \%$ vs $3.3 \%)$, but had given the significant advantage in myocardial infarction (2.2\% vs $4.7 \%)$. The AQUARIUS Randomized Clinical Trial indicated that aliskiren therapy did not result in improvement or slowing of progression of coronary atherosclerosis, and has no significant effect on the risk of major cardiovascular outcomes. ${ }^{24}$ The possible reason for 
Table 2 Subgroup analysis for the effect of aliskiren therapy on major cardiovascular events and total mortality

\begin{tabular}{|c|c|c|c|c|c|c|}
\hline Outcomes & Subgroup & $\begin{array}{l}\text { Number of } \\
\text { included studies }\end{array}$ & $\mathbf{R R}$ and $95 \% \mathrm{Cl}$ & $P$-value & $\begin{array}{l}\text { Heterogeneity } \\
\text { (\%) }\end{array}$ & $\begin{array}{l}P \text {-value for } \\
\text { heterogeneity }\end{array}$ \\
\hline Major & Current disease status & & & & & \\
\hline cardiovascular & CVD & 4 & $0.84(0.63-1.12)$ & 0.23 & 55 & 0.08 \\
\hline \multirow[t]{7}{*}{ events } & Without CVD & I & $1.10(0.98-1.22)$ & 0.09 & - & - \\
\hline & Control & & & & & \\
\hline & ACE inhibitor & 2 & $0.94(0.82-1.06)$ & 0.31 & 0 & 0.73 \\
\hline & Both & 3 & $0.88(0.58-1.35)$ & 0.56 & 80 & 0.007 \\
\hline & The duration of follow-up & & & & & \\
\hline & 12 months or more & 2 & $0.78(0.38-1.61)$ & 0.51 & 90 & 0.002 \\
\hline & $<12$ months & 3 & $0.95(0.84-1.07)$ & 0.37 & 0 & 0.79 \\
\hline \multirow[t]{9}{*}{ Total mortality } & Current disease status & & & & & \\
\hline & CVD & 4 & $0.9 I(0.45-\mid .8 I)$ & 0.78 & 62 & 0.05 \\
\hline & Without CVD & 2 & $0.93(0.40-2.19)$ & 0.87 & 14 & 0.28 \\
\hline & Control & & & & & \\
\hline & ACE inhibitor & 3 & $0.96(0.79-1.18)$ & 0.73 & 0 & 0.59 \\
\hline & Both & 3 & $0.89(0.36-2.20)$ & 0.80 & 75 & 0.02 \\
\hline & The duration of follow-up & & & & & \\
\hline & 12 months or more & 2 & $0.49(0.08-2.90)$ & 0.43 & 83 & 0.02 \\
\hline & $<12$ months & 4 & I.06 (0.73-I.54) & 0.77 & 16 & 0.31 \\
\hline
\end{tabular}

Notes: Entry criteria: participants aged 18 years or older, with systolic blood pressure between 110 and $139 \mathrm{mmHg}$, and diastolic blood pressure between 70 and $89 \mathrm{mmHg}$.

Abbreviations: $\mathrm{ACE}$, angiotensin-converting enzyme; CVD, cardiovascular disease; RR, relative risk; $\mathrm{Cl}$, confidence interval.

this lack of significant effect could be that relatively few trials reported these outcomes, contributing to broad CIs. Furthermore, the trials always reported cardiovascular outcomes that needed more than 12 months follow-up, but only two of six included trials had greater than 12 months follow-up periods.

Previous meta-analysis ${ }^{27,28}$ suggested that aliskiren therapy was associated with an increased risk for hyperkalemia. However, the study did not observe the efficacy of combination therapy on cardiovascular events. In the present study, we observed the efficacy of aliskiren therapy on major cardiovascular outcomes. The results of our meta-analysis

\section{A}

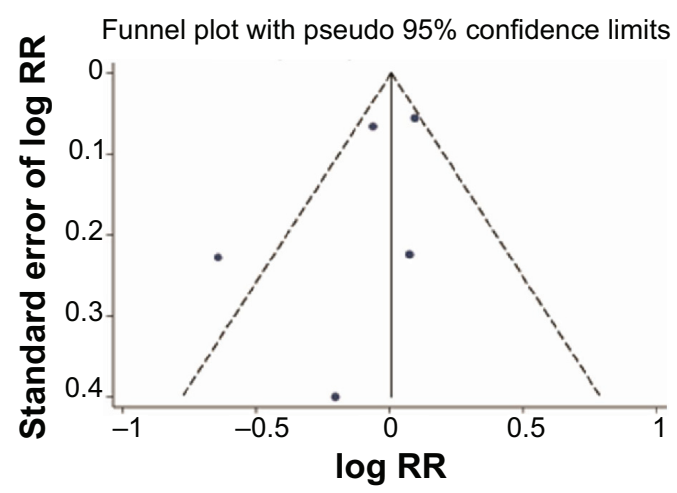

$P$-value for Egger et al ${ }^{19}: 0.322 ; P$-value for Begg et $a^{20}: 0.462$ suggested that aliskiren therapy does not have an effect on the risk of major cardiovascular events, total mortality, cardiac death, myocardial infarction, and stroke. Subgroup analysis also supports that aliskiren therapy has no significant effect on the risk of major cardiovascular events and total mortality. Hence, clinicians should be cautioned about the use of aliskiren in patients with high BP recognizing that there are no benefits for the use of this drug to prevent cardiovascular events.

The limitations of our study include the inherent assumptions made for any meta-analysis, because the analysis uses pooled data from published papers and original data were not

Figure 4 Funnel plot for major cardiovascular events (A) and total mortality (B). Abbreviation: RR, relative risk.

B

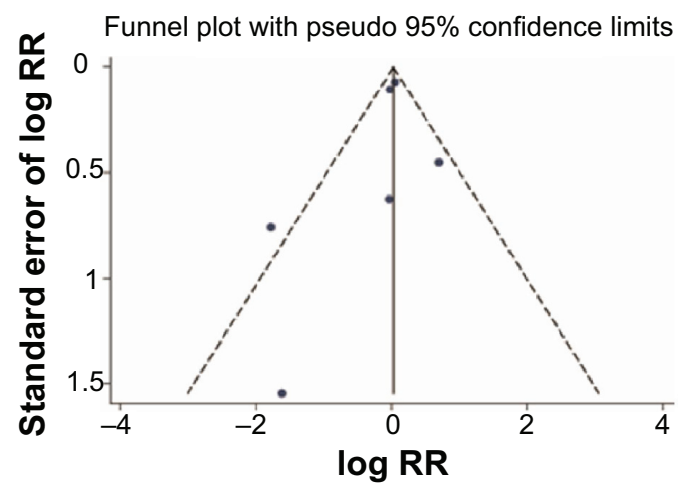

$P$-value for Egger et $a^{19}: 0.430 ; P$-value for Begg et $a^{20}: 0.260$ 
available. Furthermore, data on major cardiovascular outcomes were available from few trials, which made the conclusions potentially unreliable. We therefore provided a relative result by comparing aliskiren therapy and ACEI or ARB therapy, and provided a synthetic and comprehensive review.

\section{Conclusion}

In conclusion, the findings of our study suggest that aliskiren therapy has no beneficial effect on major cardiovascular events, total mortality, cardiac death, myocardial infarction, and stroke. Though the use of aliskiren could control BP effectively, there are no benefits for the use of this drug to prevent cardiovascular events. For future study, promising interventions should be tested, including dosage, duration of treatment, or combination with other ARB or ACE inhibitors. We suggest that ongoing trials should be improved in the following ways: 1) it will be important to focus on the patients' baseline characteristics, especially for current disease status. 2) The role of treatment duration and dosage should be taken into consideration before evaluating clinical outcomes.

\section{Disclosure}

The authors received no financial support for the research, authorship, and/or publication of this article. The authors report no conflicts of interest in this work.

\section{References}

1. Lewington S, Clarke R, Qizilbash N, Peto R, Collins R. Age-specific relevance of usual blood pressure to vascular mortality: a meta-analysis of individual data for one million adults in 61 prospective studies. Lancet. 2002;360(9349):1903-1913.

2. Rosamond W, Flegal K, Furie K, et al. Heart disease and stroke statistics-2008 update: a report from the American Heart Association Statistics Committee and Stroke Statistics Subcommittee. Circulation. 2008;117(4):e25-e146.

3. Persson F, Lewis JB, Lewis EJ, Rossing P, Hollenberg NK, Hans-Henrik P. Impact of aliskiren treatment on urinary aldosterone levels in patients with type 2 diabetes and nephropathy: an AVOID substudy. J Renin Angiotensin Aldosterone Syst. 2012;13(1): $118-121$.

4. Jeunemaitre X, Menard J, Nussberger J, Guyene TT, Brunner HR, Corvol P. Plasma angiotensins, renin, and blood pressure during acute renin inhibition by CGP $38560 \mathrm{~A}$ in hypertensive patients. Am J Hypertens. 1989;2(11 Pt 1):819-827.

5. Azizi M, Menard J. Combined blockade of the renin-angiotensin system with angiotensin-converting enzyme inhibitors and angiotensin II type 1 receptor antagonists. Circulation. 2004;109(21):2492-2499.

6. Jamerson KA, Nwose O, Jean-Louis L, Schofield L, Purkayastha D, Baron M. Initial angiotensin-converting enzyme inhibitor/calcium channel blocker combination therapy achieves superior blood pressure control compared with calcium channel blocker monotherapy in patients with stage 2 hypertension. Am J Hypertens. 2004;17(6):495-501.

7. Poldermans D, Glazes R, Kargiannis S, et al. Tolerability and blood pressure-lowering efficacy of the combination of amlodipine plus valsartan compared with lisinopril plus hydrochlorothiazide in adult patients with stage 2 hypertension. Clin Ther. 2007;29(2): 279-289.
8. Gradman AH, Schmieder RE, Lins RL, Nussberger J, Chiang Y, Bedigian MP. Aliskiren, a novel orally effective renin inhibitor, provides dose-dependent antihypertensive efficacy and placebo-like tolerability in hypertensive patients. Circulation. 2005;111(8):1012-1018.

9. Parving HH, Brenner BM, McMurray JJ, et al. Cardiorenal End Points in a Trial of Aliskiren for Type 2 Diabetes. N Engl J Med. 2012;367(23): 2204-2213.

10. Flack JM, Yadao AM, Purkayastha D, Samuel R, White WB. Comparison of the effects of aliskiren/valsartan in combination versus valsartan alone in patients with Stage 2 hypertension. J Am Soc Hypertens. 2012; 6(2):142-151.

11. Gheorghiade M, Böhm M, Greene SJ, et al. Effect of Aliskiren on Postdischarge Mortality and Heart Failure Readmissions Among Patients Hospitalized for Heart Failure The ASTRONAUT Randomized Trial. JAMA. 2013;309(11):1125-1135.

12. Makani H, Bangalore S, Desouza KA, Shan A, Messerli FH. Efficacy and safety of dual blockade of the renin-angiotensin system: metaanalysis of randomised trials. BMJ. 2013;346:f360.

13. Moher D, Liberati A, Tetzlaff J, Altman DG; PRISMA Group. Preferred Reporting Items for Systematic Reviews and Meta-Analyses: The PRISMA Statement. PLoS Med. 2009;6(7):e1000097.

14. Jadad AR, Moore RA, Carroll D, et al. Assessing the quality of reports of randomized clinical trials: is blinding necessary? Control Clin Trials. 1996;17(1):1-12.

15. Kones R. Primary prevention of coronary heart disease: integration of new data, evolving views, revised goals, and role of rosuvastatin in management. A comprehensive study. Drug Des Devel Ther. 2011;5: 325-380.

16. Ades AE, Lu G, Higgins JP. The interpretation of random-effects meta-analysis in decision models. Med Decis Making. 2005;25(6): 646-654.

17. Deeks JJ, Higgins JP, Altman DG. Analyzing data and undertaking meta-analyses. In: Higgins J, Green S, editors. Cochrane Handbookfor Systematic Reviews of Interventions 5.0.1. Oxford, UK: The Cochrane Collaboration; 2008.

18. Higgins JP, Thompson SG, Deeks JJ, Altman DG. Measuring inconsistency in meta-analyses. BMJ. 2003;327(7414):557-560.

19. Egger M, Davey Smith G, Schneider M, Minder C. Bias in metaanalysis detected by a simple, graphical test. BMJ. 1997;315(7109): 629-634.

20. Begg CB, Mazumdar M. Operating characteristics of a rank correlation test for publication bias. Biometrics. 1994;50(4):1088-1101.

21. Parving HH, Persson F, Lewis JB, Lewis EJ, Hollenberg NK; AVOID study investigators. Aliskiren Combined with Losartan in Type 2 Diabetes and Nephropathy. N Engl J Med. 2008;358(23):2433-2446.

22. Scirica BM, Morrow DA, Bode C, et al. Patients with acute coronary syndromes and elevated levels of natriuretic peptides: the results of the AVANT GARDE-TIMI 43 Trial. Eur Heart J. 2010;31(16): 993-2005.

23. Solomon SD, Shin SH, Shah A, et al. Effect of the direct renin inhibitor aliskiren on left ventricular remodelling following myocardial infarction with systolic dysfunction. Eur Heart J. 2011;32(10):1227-1234.

24. Nicholls SJ, Bakris GL, Kastelein JJ, et al. Effect of Aliskiren on Progression of Coronary Disease in Patients With Prehypertension The AQUARIUS Randomized Clinical Trial. JAMA. 2013;310(11):1135-1144.

25. Pool JL, Schmieder RE, Azizi M, et al. Aliskiren, an Orally Effective Renin Inhibitor, Provides Antihypertensive Efficacy Alone and in Combination With Valsartan. Am J Hypertens. 2007;20(1):11-20.

26. Gao D, Ning N, Niu X, Wei J, Sun P, Hao G. Aliskiren vs. angiotensin receptor blockers in hypertension: meta-analysis of randomized controlled trials. Am J Hypertens. 2011;24(5):613-621.

27. Harel Z, Gilbert C, Wald R, et al. The effect of combination treatment with_aliskiren_and blockers of the renin-angiotensin system on hyperkalaemia and acute kidney injury: systematic review and- meta-analysis. BMJ. 2012;344(1):e42.

28. Nathan SD, King CS. Treatment of pulmonary hypertension in idiopathic pulmonary fibrosis: shortfall in efficacy or trial design? Drug Des Devel Ther. 2014;8:875-885. 


\section{Publish your work in this journal}

Drug Design, Development and Therapy is an international, peerreviewed open-access journal that spans the spectrum of drug design and development through to clinical applications. Clinical outcomes, patient safety, and programs for the development and effective, safe, and sustained use of medicines are a feature of the journal, which has also been accepted for indexing on PubMed Central. The manuscript management system is completely online and includes a very quick and fair peer-review system, which is all easy to use. Visit http://www.dovepress.com/testimonials.php to read real quotes from published authors.

Submit your manuscript here: http://www.dovepress.com/drug-design-development-and-therapy-journal 